\title{
Reduction of bacterial regrowth in treated water by minimizing water stagnation in the filtrate line of a gravity-driven membrane system
}

\author{
JongChan Yi, Jonghun Lee, Hyejin Jung, Pyung-Kyu Park, Soo Hong Noh ${ }^{\dagger}$ \\ Department of Environmental Engineering, Yonsei University, Wonju 26493, Republic of Korea
}

\begin{abstract}
This study monitored changes in the level of heterotrophic bacteria in the filtrate and investigated the effect of stagnant water on it, using a batch-operated, gravity-driven membrane system for household water treatment. The filtration test was carried out in the presence and absence of stagnant water in the filtrate line. The results showed that stagnant water accelerated the heterotrophic bacteria levels, measured by heterotrophic plate count, even though the heterotrophic plate count of the filtrate finally increased up to $10^{5} \mathrm{CFU} / \mathrm{mL}$ regardless of the presence of stagnant water. When the change in heterotrophic plate count of a batch was monitored over filtration time, heterotrophic plate count of the filtrate rapidly decreased within $5 \mathrm{~min}$ for each batch filtration. Biofilm formation on the filtrate line was observed in the presence of stagnant water. The biofilm fully covered the filtrate line and contained numerous microorganisms. During storage after filtration, heterotrophic plate count increased exponentially. To improve the filtrate quality of a filtration-based household water treatment system, therefore, the stagnant water in the filtrate line should be minimized, the filtrate produced at the first 5 min is recommended not to be used as potable water, and the storage of filtrate should be avoided.
\end{abstract}

Keywords: Bacterial growth, Gravity-driven membrane (GDM), Heterotrophic plate count, Household water treatment (HWT)

\section{Introduction}

Bacteria are often found in drinking water despite disinfection. This is unsurprising, since biofilms are commonly found on surfaces exposed to aquatic environments even in drinking water distribution systems [1]. When chlorination is applied as disinfection, residual chlorine suppresses bacterial regrowth in water distribution systems. However, bacterial regrowth may become significant when insufficient amount of residual chorine remains, or when UV radiation or membrane filtration processes are used for disinfection in the absence of parallel or subsequent chlorination. Membrane filtration basically results in complete exclusion of particles, including microorganisms, the size of which is smaller than the membrane pore size. However, microorganisms can be found from filtrate because nutrients may not be totally rejected by membrane and may lead to bacterial regrowth when filtrate is compromised by microbial inflow after filtration. Thus, bacterial growth has been observed even after Nanofiltration [2]. Also, the number of cells in treated water has been reported up to 6 log cells per $\mathrm{mL}$ even after membrane filtration [3].

Bacterial regrowth after treatment can particularly be a notable problem in household water treatment (HWT) systems, especially, in developing countries. HWT systems were introduced in many studies and used widely as an appropriate technology [4-7]. Most of these systems are small and operable without electricity. HWT systems have advantages such as minimal parts, easy handling, and affordable cost. The typical examples of the HWT systems are filtration processes using polymeric microfiltration membrane or ceramic filter operated by water head and adsorption processes using activated carbon and other adsorbents. Especially, filtration-based HWT system can significantly improve drinking water quality and are considered as an effective intervention to reduce diarrheal diseases [8].
This is an Open Access article distributed under the terms of the Creative Commons Attribution Non-Commercial License (http://creativecommons.org/licenses/by-nc/3.0/) which permits unrestricted non-commercial use, distribution, and reproduction in any medium, provided the original work is properly cited.

Copyright (C) 2019 Korean Society of Environmental Engineers
Received January 25, 2018 Accepted May 3, 2018

${ }^{\dagger}$ Corresponding author

Email: drnoh@yonsei.ac.kr

Tel: +82-33-760-2420 Fax: +82-33-760-2571

ORCID: 0000-0001-8446-2840 
However, it does not mean that health risks of users are completely removed because the filtrate can be contaminated after filtration. Rufener et al. reported microbial deterioration of drinking water after treatment and emphasized needs of safe storage and handling to prevent post-treatment contamination [9]. In many cases, filtration-based HWT systems such as ceramic pot filters, ceramic candle filters, Safir filter, and LifeStraw ${ }^{\circledR}$ family, have a storage tank to overcome low filtrate flow rate [10-14]. However, the storage tanks were vulnerable to regrowth of bacteria due to poor removal of dissolved carbon, a substrate source for the microorganism. System maintenance, such as disinfection, was often neglected because of lack of resources, especially, in the developing countries. Furthermore, the systems are frequently operated in batch sequential mode. Therefore, the systems may have been exposed to bacterial growth in the filtrate line, storage tank, or both, owing to water stagnation during standstill time between producing batches of treated water. A risk of post-treatment contamination during standstill time was reported by several researchers. Peter mentioned a possibility of bacterial regrowth and recontamination after filtration in a small gravity-driven membrane (GDM) filtration system [13]. Rufener et al. report that the quality of water could frequently be worsened before drinking despite the water quality was improved by HWT [9]. However, experimental studies on bacterial regrowth in HWT systems have been hardly found despite the recent increase in the supply and usage of HWT systems in developing countries, and, to the best of our knowledge, there are few options that can be applicable to the problem.

Therefore, the objective of this study was to develop appropriate operating methods for reduction in bacterial growth in treated water of an end-free GDM system used as a HWT system. The effect of stagnation water in the filtrate line of the system on bacterial growth was explored during filtration and storage. Filtrate recontamination was investigated by observing heterotrophic bacteria count (HPC). Even though HPC values alone are not directly related to health risk $[15,16]$, heterotrophic bacteria growth is a practical and inexpensive technique and can be an indicator that represents the growth of pathogenic microorganisms [16, 17]. The surfaces of the filtrate line and membrane were analyzed using a field emission scanning electron microscope (SEM) to observe bacteria on the surfaces.

\section{Materials and Methods}

\subsection{Raw Water}

A water sample taken from a groundwater source at Wonju City in the Republic of Korea was used as raw water. Average $\mathrm{pH}$ and HPC were 6.34 and $139 \mathrm{CFU} / \mathrm{mL}$, respectively. On the other hand, Escherichia coli (E. coli) or coliforms was not found from raw water. Chlorine was undetectable in the raw water throughout the experiments. Dissolved organic carbon (DOC) of the raw water was approximately $5.6 \pm 0.4 \mathrm{mg} / \mathrm{L}$.

\subsection{Experimental Set-up}

The two identical end-free GDM systems used in the filtration test are shown in Fig. 1. Each system was equipped with an end-free GDM module consisting of a header, a cylindrical housing, and commercial hollow fiber membranes (Econity, Republic of Korea). Only one end of each membrane fiber was potted to the header, and the other was individually sealed for free movement inside the module [18]. The module was connected to a 20-L jerrycan via the screw on the header. The jerrycan was filled with raw water before connecting the module, and the filtrate flowed through silicon tubing connected to the header. The jerrycan had a vent hole on the top, and thus raw water was filtrated by the water head, i.e. gravity-driven filtration. The systems were placed in a temperature-controlled room at $20 \pm 3^{\circ} \mathrm{C}$. The specifications of the system are shown in Table 1 .

Table 1. Specifications of the End-free GDM System

\begin{tabular}{lr}
\hline Membrane area & $0.3 \mathrm{~m}^{2}$ \\
Membrane inner/outer diameter & $0.66 / 1.23 \mathrm{~mm}$ \\
Membrane pore size & $0.157 \mu \mathrm{m}$ \\
Membrane material & Polyvinylidene fluoride \\
Silicon tubing inner/outer diameter & $6 / 9 \mathrm{~mm}$ \\
Silicon tubing length & $350 \mathrm{~mm}$ \\
\hline
\end{tabular}

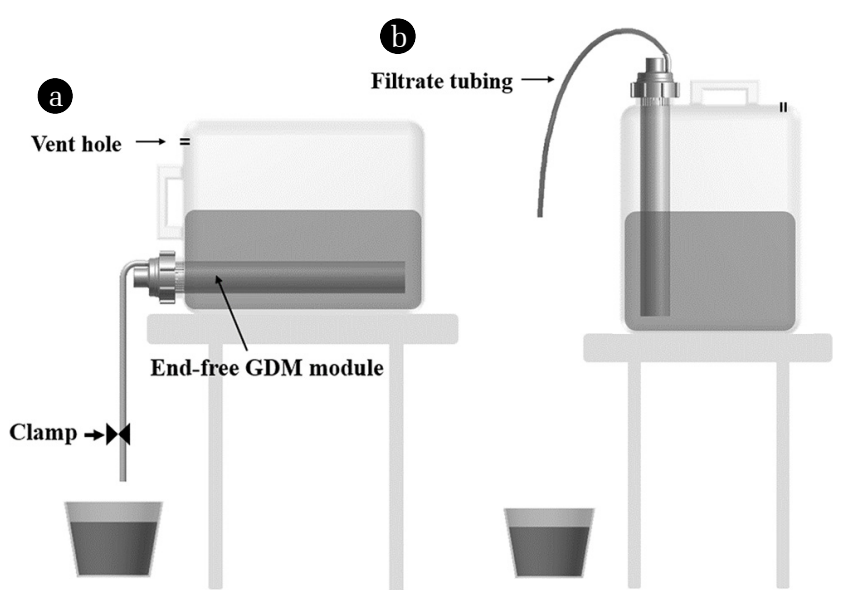

Fig. 1. GDM filtration systems consisting of an end-free GDM module and a $20-\mathrm{L}$ jerrycan (a) in the presence of stagnant water inside the permeate tubing when filtration was ceased by clamping the tubing and (b) in the absence of stagnant water when filtration was ceased by standing the jerrycan on end.

\subsection{Experimental Procedure}

Before filtration experiments, the systems including the filtrate tubing and membrane module, were sterilized using a 100-ppm chlorine solution to deactivate microorganisms inside the system. As mentioned above, the system was operated in batch filtration mode. One batch filtration was carried out every day for 28 d. The average filtration time of each batch was around $1 \mathrm{~h}$, and the cumulative filtration volume per batch was approximately $13 \mathrm{~L}$. Concentrate in the jerrycan was not drained till the end of the filtration experiment. During the remaining time in each day, designated "standstill time" here, filtration was 
stopped by clamping the tubing for one system (Fig. 1(a)) or by simply standing the jerrycan on end without clamping for the other (Fig. 1(b)). The former system held stagnant water in the filtrate tubing whereas the latter did not, as filtrate almost completely drained out of the tubing. After the end of the filtration experiment, filtrate bacterial growth during water storage was monitored by HPC. In this experiment, a chlorinated GDM module (3,000 ppm NaOCl for $10 \mathrm{~min})$ and a sterilized storage bottle were used to prevent bacteria from contaminating the module and bottle.

\subsection{Heterotrophic Plate Count and Escherichia coli Cultivation}

Heterotrophic bacteria cultures were prepared on nutrient agar (Becton Dickinson, USA) using the spread plate method. Dilutions, when necessary, were carried out using $0.001 \mathrm{M}$ phosphate-buffered saline (PBS, $0.75 \% \mathrm{NaCl}$ ). Each sample was plated at least in duplicate, to avoid unsuspected data loss. The plates were incubated at $37^{\circ} \mathrm{C}$ for $48 \mathrm{~h}$. The results of HPC are presented as $\mathrm{CFU} / \mathrm{mL}$. For observing pathogenic microbial growth from filtrate, E. coli cultivation was conducted using E. coli/coliform count plate kits $\left(3 \mathrm{M}^{\mathrm{TM}}\right.$ Petrifilm $^{\mathrm{TM}}, 3 \mathrm{M}$, USA).

\subsection{SEM Analysis}

After the filtration test, the silicon tubing and hollow fiber membrane of the system were analyzed using a field emission scanning electron microscope (FE-SEM, Quanta FEG 250, FEI, USA). Each sample was fixed in $4 \%$ glutaraldehyde with the phosphate buffer for $12 \mathrm{~h}$. After fixation, the samples were immersed in $20 \%$, $50 \%$, and $100 \%$ ethyl alcohol, sequentially, for dehydration. Specimens were coated with Pt using a sputter coater (Cressington Scientific Instruments Ltd., England), before SEM analysis.

\subsection{Integrity Test of the Module and DOC Analysis}

The integrity of the GDM module was examined by a pressure decay test [19]. Pressure of $0.18 \mathrm{MPa}$ was applied to the module, and then pressure decay was observed for $5 \mathrm{~min}$. A total organic carbon analyzer (TOC-V CPH/CPN, Shimadzu, Japan) was used to analyze DOC of water samples. All water samples were filtered by a syringe filter (Cellulose Acetate, $0.22 \mu \mathrm{m}$, Chromafil, Macherey-nagel, Germany) before DOC analysis.

\section{Results and Discussion}

\subsection{Effects of Stagnant Water on Bacteria Growth}

A large number of heterotrophic bacteria were found in the filtrate, despite filtration by a membrane with a pore size $(0.157$ $\mu \mathrm{m})$ small enough to sift out all the bacteria. Chlorination of the systems was performed for disinfection before the filtration test, as mentioned previously. When module integrity was tested before and after filtration, no defect was found. The bacteria in the filtrate might have originated from another source, for instance, the air or dust through the end of the silicon tubing instead of through the membrane. It should be noted that, in practice, it is almost impossible to operate HWT systems in a bacteria-free environment. In many cases, therefore, detection of bacteria in the filtrate was possible even after complete treatment in terms of microorganisms. On the other hand, E. coli and coliform were not found from the filtrate during whole experiments (Fig. S1 in the supplementary information) because $E$. coli and coliform were not found from raw water used in this study and there was no intentional fecal inoculation or unintentional fecal exposure. For this reason, we used HPC as an indicator to observe water quality of the system even though $E$. coli and coliform are still good indicators to evaluate biological water quality.

Fig. 2 shows the filtrate HPC results during the filtration test. The HPC data in Fig. 2(a) and 2(b) correspond to the filtrate sampled at the beginning of each batch filtration, and to the filtrate sampled at $5 \mathrm{~min}$ after each filtration began, respectively. In Fig. 2(a), HPC values at $0 \mathrm{~min}$ were 10 to 1,000 times higher in the presence of stagnant water than those measured in the absence of stagnant water before 19 batches, after which, the HPC values became similar to each other. HPC plateaued at around $10^{5} \mathrm{CFU} / \mathrm{mL}$ for both cases, but reached the maximal level faster for the former than the latter. This means that stagnant water was a factor for increasing HPC when the first filtrate was dispensed for each batch. It seems that bacteria growth was promoted by the presence of stagnant water, whereas growth
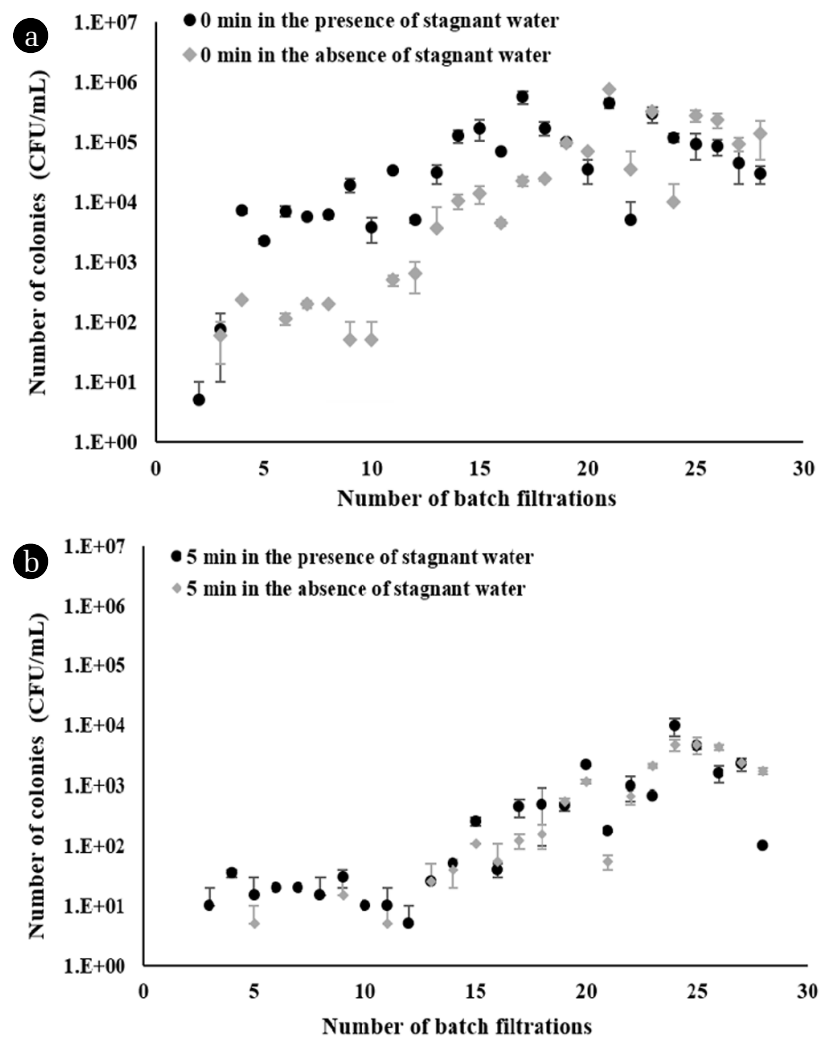

Fig. 2. HPC in the filtrate for two cases: Filtrate samples were taken (a) at the beginning of each batch and (b) at 5 min after the start of each filtration. 
was suppressed by air drying in the absence of stagnant water between batch filtration. However, the air drying did not lead to deactivation of bacteria, and thus the first filtrate HPC in the absence of stagnant water became similar to that in presence of stagnant water after 19 batches. On the other hand, no significant differences in HPC were observed between the two cases for the filtrate samples taken 5 min later, as shown in Fig. 2(b). It implies that most of bacteria releasing after 5 min did not originate directly from the stagnant water but came from bacterial colonies or biofilms formed on the inside surface of the filtrate tubing. We focused on the fact that the HPC values at $5 \mathrm{~min}$ were 10 to 100 times lower those values at $0 \mathrm{~min}$. Therefore, the HPC variation of the filtrate was monitored as a function of filtration time in three of the 28 batches.

\subsection{Changes in HPC Value by Filtration Time}

Three batches $\left(13^{\text {th }}, 23^{\text {rd }}\right.$, and $28^{\text {th }}$ batches $)$ from the total 28 batches filtration tests were selected to investigate HPC variations as a function of filtration time, as shown in Fig. 3. No differences between the two cases were found in the HPC kinetics. For both cases and for each batch, HPC values significantly decreased within $5 \mathrm{~min}$, and then HPC values were relatively stable until the end of the filtration time. This HPC pattern may have resulted from the flushing of bacteria by filtrate flow from the membrane module. It seems that the bacteria attached to the surface of the filtrate tubing were released into the filtrate. Lautenschlager et al.
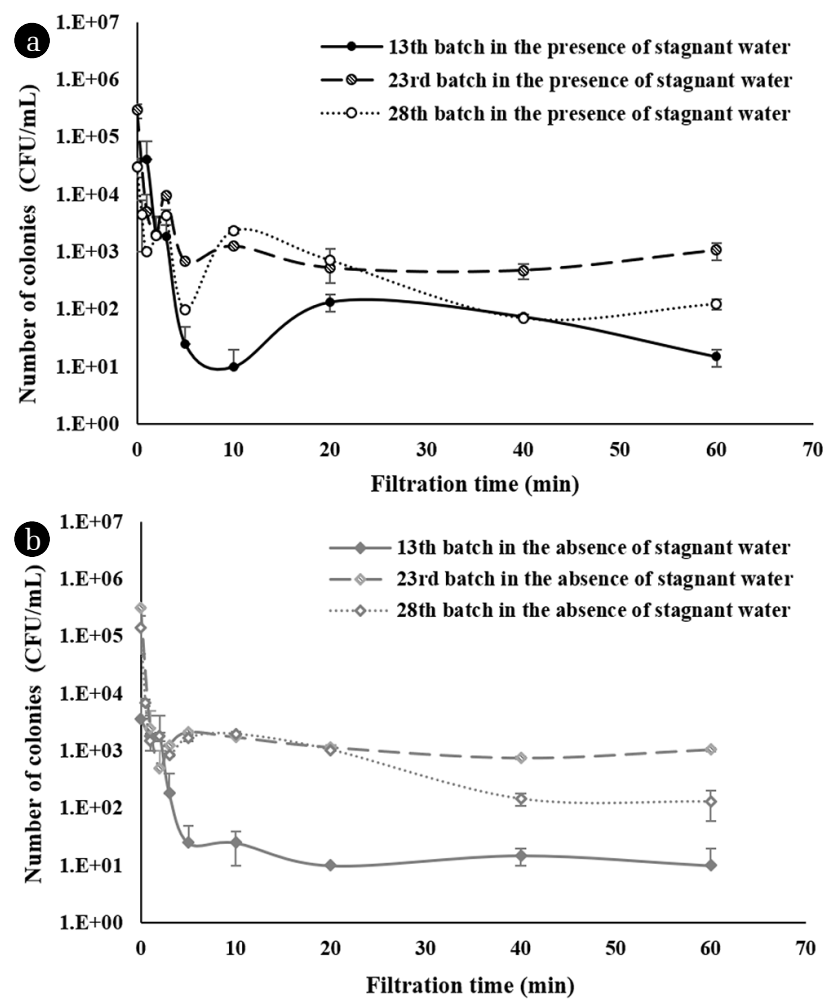

Fig. 3. HPC in the filtrate as a function of filtration time for three selected batches $\left(13^{\text {th }}, 23^{\text {rd }}\right.$, and $28^{\text {th }}$ batches in Fig. 2). (a) in the presence of stagnant water, and (b) in the absence of stagnant water. studied bacterial growth in household taps during water stagnation, and reported that high numbers of bacterial cells (around $10^{3} \mathrm{CFU} / \mathrm{mL}$ ) decreased to $9.1 \pm 9.8 \mathrm{CFU} / \mathrm{mL}$ after a 5 -min flush [20]. When only considering the efficiency of flushing and avoiding water stagnation, a constant flow system could be one solution. However, a constant flow system requires filtrate storage, which can cause another problem that is discussed below in section 3.4.

In this study, the stable HPC level was approximately 10 $\mathrm{CFU} / \mathrm{mL}$ at $13 \mathrm{~d}$, but this increased to approximately 1,000 $\mathrm{CFU} / \mathrm{mL}$ after $23 \mathrm{~d}$ of operation (Fig. 3). The WHO recommend that HPC bacterial levels should be no more than $500 \mathrm{CFU} / \mathrm{mL}$, to reduce aesthetic problems such as unpleasant tastes and odors and to prevent interference in opportunistic bacteria detection [15]. Conformance to WHO guidelines attainable in the end-free GDM system by discarding the initial 5 min filtrate, up until 13 batches of operation (based on Fig. 2(b) and Fig. 3). After 13 batches, bacteria levels could be higher than this recommendation even in the absence of stagnant water. Regular replacement or disinfection of the filtrate tubing using a chlorine tablet, for instance, could resolve this problem. The disinfection period would be dependent on conditions such as the quantity and types of microorganisms in the air, temperature, and organic carbon concentration in the source water. Many reports have documented that the organic carbon content in the water is a limiting factor for bacterial growth [21-23]. Water quality deterioration due to bacterial growth was, however, also reported with very low organic carbon concentrations (less than $0.1 \mathrm{mg} / \mathrm{L}$ biodegradable dissolved organic carbon) [21-23]. In this study, DOC of raw water was around $5.6 \mathrm{mg} / \mathrm{L}$ which was enough for bacterial growth even considering only biodegradable portion of the carbon. HWT systems are often used alone for direct water treatment. Thus, it is very difficult to reduce organic carbon in the filtrate to control microbial regrowth. Considering practicality, regular disinfection can therefore be one of the best ways to minimize deterioration of water quality as a long-term management strategy while avoiding the usage of the first-5-min filtrate for direct potable purpose (and, instead, using it for other non-potable purposes) could be a potential short-term management solution.

\subsection{Observation of Bacteria on the Surface of Filtrate Tubing and Membrane}

Fig. 4 shows SEM images of the inner surface of the filtrate tubing and the inner membrane surface, for both cases. There was a significant difference between the images of the silicon tubing in presence (Fig. 4(a)) and absence (Fig. 4(b)) of stagnant water. Microorganism colonies widely covered the silicon tubing in former case, whereas microorganisms were not found in the latter case. The difference between the two cases would have mainly resulted from the water contact time. It has been known that in biofilm formation, there is a linear relationship between water exposure time and biomass [24]. The silicon tubing, in the absence of stagnant water, was exposed to the water for one hour in a day, and to the air for twenty-three hours in a day, while the other case (presence of stagnant water) was 


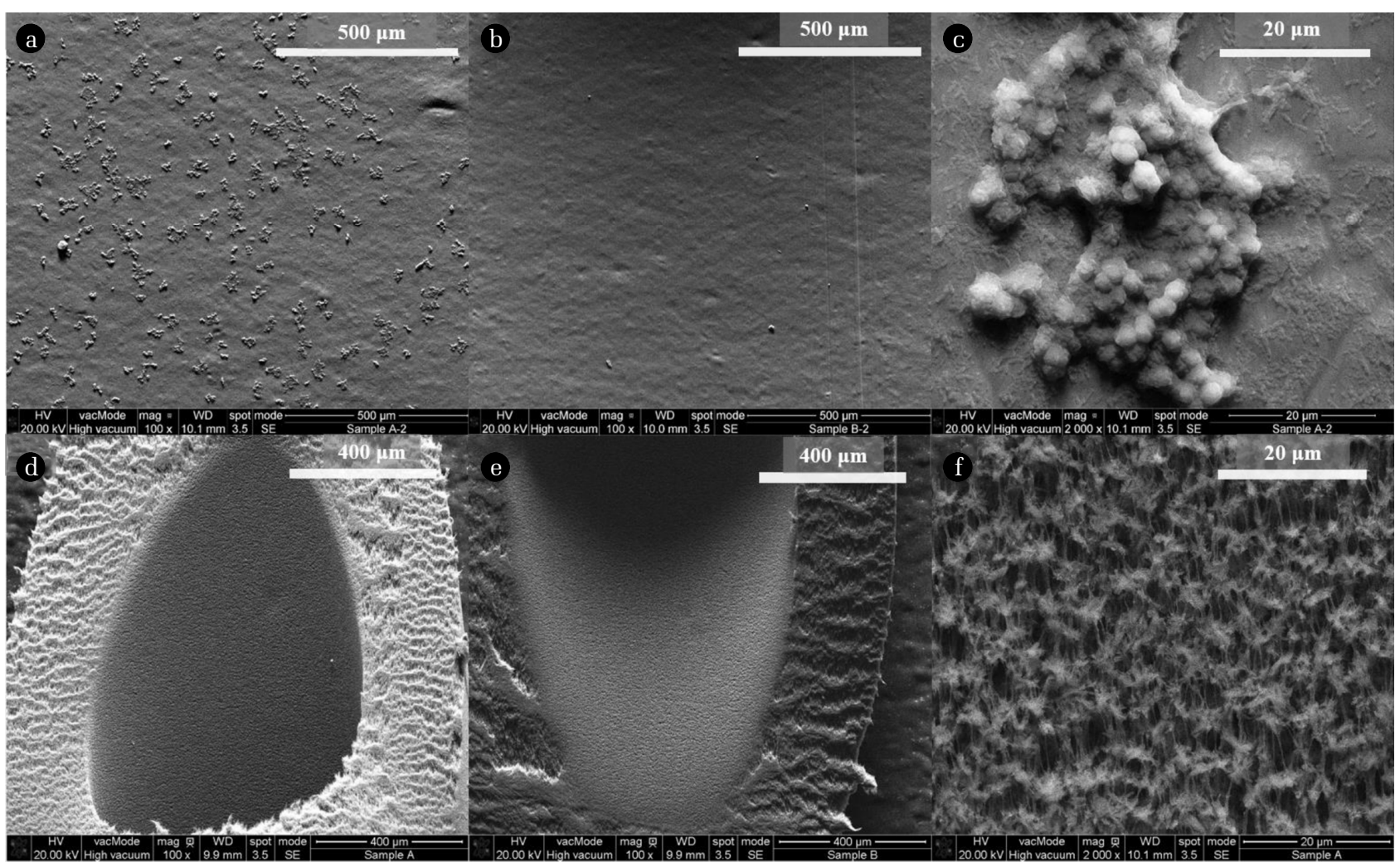

Fig. 4. SEM images of the silicon tubing inner surface and the membrane inner surface. Images (a) to (c) show the silicon tubing inner surface, and images (d) to $(f)$ show the membrane inner surface. Images (a), (c), (d), and ( $f$ ) are in the presence of stagnant water, and images (b) and (e) are in the absence of stagnant water. Images (c) and (f) are magnified versions of images (a) and (d), respectively.

exposed to water for the entire day. It is well known that biofilms can shelter opportunistic bacteria, and be substrates [1, 15, 17, $21,25]$. Thus, unnecessary stagnant water should be avoided to impede bacterial growth.

Fig. 4(d) and (e) show the inner membrane surface in the presence and absence of stagnant water, respectively. In contrast to Fig. 4(a) corresponding to the tubing surface in the presence of stagnant water, no microorganisms were distinctly found in SEM images of the membrane. Thus, it was confirmed that the origin of bacteria was not the filtrate filtered through the membrane, but that bacteria existing on the silicon tube came from the air. The image (c) (a magnified image of (a)) in Fig. 4 shows that the microorganisms covering the silicon surface were likely to be species included in the genus Micrococcus and Bacillus. The size of round-shape cell was around $2 \mathrm{~mm}$, and the size of rod-shape cell was around 0.5 and $2 \mathrm{~mm}$ for minor and major length, respectively. The Fig. 4(f) had the same magnification as the Fig. 4(c), it was hard to recognize any Micrococcus or Bacillus in the Fig. 4(f).

As mentioned in the introduction, many HWT systems had storage tanks to overcome low flow rate. Thus, filtrate quality can be easily deteriorated in the storage tank when soluble substrates were not removed fully. In this study, furthermore, bacterial regrowth was found even in the system without storage tank, because of remaining water inside the module or system.
Therefore, minimizing stagnant water and avoiding the first 5 min filtrate can be essential to simply and effectively reduce the bacteria in the filtrate to acceptable level.

\subsection{Bacterial Growth Rate during Filtrate Storage}

Bacterial growth was monitored during filtrate storage. $20 \mathrm{~L}$ of the filtrate were collected in a sterilized bottle, which was stored at $25^{\circ} \mathrm{C}$. Fig. 5 shows the variation in heterotrophic bacteria and DOC in the collected bottle as a function of storage time. DOC of the collected filtrate was about $6.6 \pm 0.9 \mathrm{mg} / \mathrm{L}$. It was slightly higher than that of raw water because of concentration in the jerrycan but did not change much during storage. HPC values increased exponentially, and it took approximately 8.5 $\mathrm{h}$ for each 10 -fold increase. The results showed that even if the filtrate contained just a few bacteria, storing the water for more than one day at room temperature with a certain amount of nutrients could lead to unacceptable HPC. Camper et al. (1991) showed growth kinetics of a few kind of coliforms. The coliforms increased by 10-fold within 10-70 $\mathrm{h}$ according to the cases, and maximum growth level was around $10^{6} \mathrm{CFU} / \mathrm{mL}$ [26]. Miettinen et al. showed HPC increases by different water sources: approximately one or two days were needed to 10-fold HPC increasing [27]. Bacterial growth rate was so different by temperature, substrate concentration, essential nutrients, initial bacteria counts, and so on. In this study, HPC level was observed only for $48 \mathrm{~h}$. 


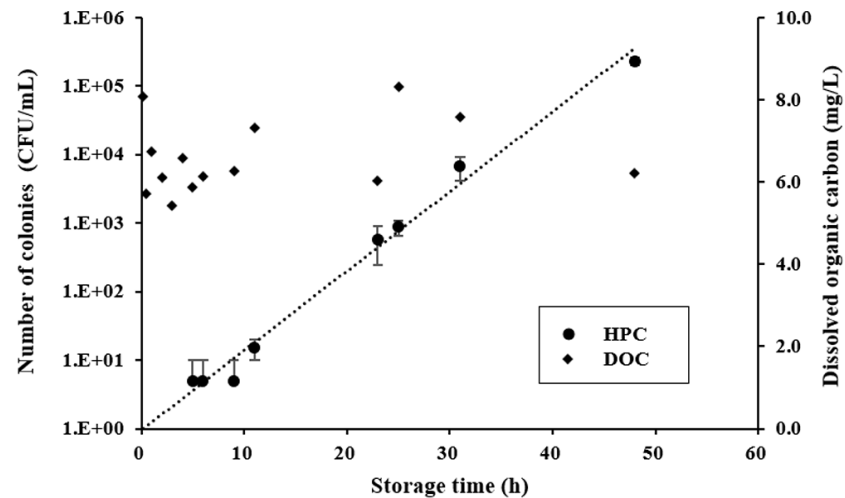

Fig. 5. HPC and DOC in the filtrate as a function of storage time at $25^{\circ} \mathrm{C}$.

Based on literatures, however, there is a chance that the HPC could increase further, more than $10^{5} \mathrm{CFU} / \mathrm{mL}$ for longer storage time. Furthermore, bacteria growth rate could be even faster than our result when environment of bacteria may fit their growth. Therefore, filtrate storage must be minimized to prevent biological contamination.

\section{Conclusions}

The relationship between the presence of stagnant water and HPC was studied using batch-operated HWT systems equipped with a GDM module per each system. Stagnant water in the silicon filtrate line accelerated the increase in filtrate HPC values. Biofilms, observed using SEM, widely covered the filtrate line in the presence of stagnant water. It will be interesting to investigate the effect of filtrate line materials on biofilm regrowth in a HWT system, which will be further studied in the future. Filtrate HPC rapidly decreased within 5 min of initial filtration. For storage of the filtrate at room temperature, HPC increased 10 -fold for every $8.5 \mathrm{~h}$. Therefore, remaining stagnant water in the system should be minimized and filtrate storage should be avoided especially when there are some substrates in the filtrate. Also, it is recommended to avoid directly drinking the first-5-min filtrate in the system and, instead, to use it for other non-potable purpose. Thus, a HWT system can be improved when it has a short filtrate line to minimize stagnant water in the system and provides high flow rate for a user to access enough amount of water without filtrate storage.

\section{Acknowledgments}

This work was financially supported by a National Research Foundation of Korea (NRF) grant funded by the Korean government (MSIT) (No. 2016R1C1B1009544) and also by the Korea Institute of Energy Technology Evaluation and Planning (KETEP) and the Ministry of Trade, Industry \& Energy (MOTIE) of the Republic of Korea (No. 20184030202240).

This article was presented at the 2017 International Environmental
Engineering Conference (IEEC2017) held on 15-17 November 2017, Jeju, Korea.

\section{References}

1. Szewzyk U, Szewzyk R, Manz W, Schleifer KH. Microbiological safety of drinking water. Annu. Rev. Microbiol. 2000;54:81-127.

2. Liu G, Lut MC, Verberk JQ, Van Dijk JC. A comparison of additional treatment processes to limit particle accumulation and microbial growth during drinking water distribution. Water Res. 2013;47:2719-2728.

3. Ho L, Braun K, Fabris R, et al. Comparison of drinking water treatment process streams for optimal bacteriological water quality. Water Res. 2012;46:3934-3942.

4. Sobsey MD, Stauber CE, Casanova LM, Brown JM, Elliott MA. Point of use household drinking water filtration: A practical, effective solution for providing sustained access to safe drinking water in the developing world. Environ. Sci. Technol. 2008;42:4261-4267.

5. Rosa G, Clasen T. Estimating the scope of household water treatment in low- and medium-income countries. Am. J. Trop. Med. Hyg. 2010;82:289-300.

6. Clasen T, Boisson S. Household-based ceramic water filters for the treatment of drinking water in disaster response: An assessment of a pilot programme in the Dominican Republic. Water Pract. Technol. 2006;1.

7. Perez-Vidal A, Diaz-Gomez J, Castellanos-Rozo J, UsaquenPerilla OL. Long-term evaluation of the performance of four point-of-use water filters. Water Res. 2016;98:176-182.

8. Wolf J, Prüss-Ustün A, Cumming O, et al. Assessing the impact of drinking water and sanitation on diarrhoeal disease in low- and middle-income settings: Systematic review and meta-regression. Trop. Med. Int. Health 2014;19:928-942.

9. Rufener S, Mäusezahl D, Mosler HJ, Weingartner R. Quality of drinking-water at source and point-of-consumption Drinking cup as a high potential recontamination risk: A field study in Bolivia. J. Health Popul. Nutr. 2010;28:34-41.

10. Van Halem D, Van der Laan H, Heijman SGJ, Van Dijk JC, Amy GL. Assessing the sustainability of the silver-impregnated ceramic pot filter for low-cost household drinking water treatment. Phys. Chem. Earth 2009;34:36-42.

11. Thomas EA, Zumr Z, Graf J, et al. Remotely accessible instrumented monitoring of global development programs: Technology development and validation. Sustainability 2013;5:3288-3301.

12. World Health Organization. Results of round I of the WHO International Scheme to evaluate household water treatment technologies. WHO; 2016.

13. Peter M. Gravity-driven membrane disinfection for household water treatment. Eawag; 2015.

14. Eawag. Evaluating the "Safir" gravity-driven membrane filter in Bolivia. Eawag: Sandec News; 2014. p. 21.

15. World Health Organization. Heterotrophic plate counts and drinking-water safety. IWA Publishing; 2003.

16. World Health Organization. Heterotrophic plate count meas- 
urement in drinking water safety management. World Health Organization; 2002.

17. Chowdhury S. Heterotrophic bacteria in drinking water distribution system: A review. Environ. Monit. Assess. 2012;184:6087-6137.

18. Yi JC, Lee JH, Noh SH. Cleaning effects induced by feed water flow of a gravity-driven membrane module. $J$. Appropriate Technol. 2016;2:47-54.

19. United States Environmental Protection Agency. Membrane filtration guidance manual. EPA; 2005.

20. Lautenschlager K, Boon N, Wang Y, Egli T, Hammes F. Overnight stagnation of drinking water in household taps induces microbial growth and changes in community composition. Water Res. 2010;44:4868-4877.

21. Escobar IC, Randall AA, Taylor JS. Bacterial growth in distribution systems: Effect of assimilable organic carbon and biodegradable dissolved organic carbon. Environ. Sci. Technol. 2001;35:3442-3447.

22. Huck PM. Measurement of biodegradable organic matter and bacterial growth potential in drinking water. J. Am. Water Works Assoc. 1990;82:78-86.

23. Volk CJ, Lechevallier MW. Impacts of the reduction of nutrient levels on bacterial water quality in distribution systems. Appl. Environ. Microbiol. 1999;65:4957-4966.

24. Van der Kooij D, Veenendaal HR, Baars-Lorist C, Van der Klift DW, Drost YC. Biofilm formation on surfaces of glass and Teflon exposed to treated water. Water Res. 1995;29: 1655-1662.

25. Mi Z, Dai Y, Xie S, Chen C, Zhang X. Impact of disinfection on drinking water biofilm bacterial community. J. Environ. Sci. 2015;37:200-205.

26. Camper AK, McFeters GA, Characklis WG, Jones WL. Growth kinetics of coliform bacteria under conditions relevant to drinking water distribution systems. Appl. Environ. Microbiol. 1991;57:2233-2239.

27. Miettinen IT, Vartiainen T, Martikainen PJ. Phosphorus and bacterial growth in drinking water. Appl. Environ. Microbiol. 1997;63:3242-3245. 